\title{
RESEARCH ON THE ORGANIZATION MODE OF URBAN JOINT DISTRIBUTION
}

\author{
R.GENG ${ }^{1}$ Z.Y. CHEN ${ }^{2}$ \\ ${ }^{1}$ RESEACH INSTITUTE OF HIGHWAY MINISTRY OF TRANSPORT, BEIJING, CHINA \\ ${ }^{2}$ RESEACH INSTITUTE OF HIGHWAY MINISTRY OF TRANSPORT, BEIJING, CHINA
}

\begin{abstract}
KEYWORD: TRANSPORTATION ENGINEERING; ORGANIZATION MODE; TRANSPORT ECONOMICS; URBAN DISTRIBUTION.
\end{abstract}

ABSTRACT: This paper reference the development experience of the joint distribution at home and abroad, research on the organization mode of typical cities. It can be divided into the proprietary distribution mode of production and trade enterprises, the professional distribution mode of logistics enterprises, the centralized distribution mode of distribution station, the joint distribution mode of information technology, and the unified distribution model of specific resources. This paper presents the basic elements, characteristic and applicable conditions of each models. It provides experiences and references for the enterprises which intends to carry out joint distribution. It also lay the foundation of government to introduce the support measures.

\section{PREFACE}

Along with the domestic and foreign logistics practice continuously enriched, "joint distribution" has exceeded the early definition, greatly expanded the connotation and extension of national standard "logistics terms" definition of the joint distribution is: many enterprises jointly organized the implementation of the distribution activities. Our practice often use other concepts such as "joint distribution" and "collaborative delivery" and "unified distribution", "centralized distribution, joint distribution" and "in connotation and no clear difference is due to the different translation of foreign literature

According to the integration of vehicles and goods of different resources, the joint distribution pattern can be divided into the production business enterprise self distribution mode, distribution mode, distribution logistics enterprise professional station centralized distribution mode of information technology, the common distribution pattern, specific resources unified distribution mode.

One by one analysis of the basic elements, characteristics and applicable conditions of the common distribution model of all kinds of cities.

\section{SELF DISTRIBUTION MODE OF PRODUCTION AND TRADE ENTERPRISES}

Single large-scale production enterprise

According to their own product sales demand for production enterprises, the use of its own vehicles (or commissioned by the logistics business), with a car carrying a number of downstream merchant orders goods, in accordance with the way to optimize the distribution of lines one by one.

1) the main production enterprises to promote product sales, to ensure the supply, distribution mode and reduce the cost of distribution and use.

2) distribution service is limited to the sales customers of the production enterprise, it is closed and the society is open.

3) production enterprises are the main body of the supply of goods, according to the demand of sales customers to develop a series of distribution lines.

4) transport routes, vehicles, delivery time and other relatively fixed.

5) general use of the production enterprise owned warehouse.

6) the model is generally formed by the market. 


\section{Single large business model}

Large business enterprises have a number of shopping malls, supermarkets, chain supermarkets and other outlets, the supplier of products focused on one or several stations, according to the jurisdiction outlets of goods distribution demand, develop the distribution plan, unified for its business outlets and distribution.

1) large commercial enterprises to meet the needs of small batch, multi batch, and a large number of times, while the common distribution model is adopted to reduce the distribution cost.

2) distribution service scope is limited to the large commercial enterprises under its stores, more closed, social openness is weak.

3) large chain business enterprise is the main body of supply organization.

4) distribution line according to the requirements of the goods stores, relatively fixed.

5 ) is generally from the distribution center to the lower reaches of the store's transport using a common distribution model, the upper reaches of the vehicle distribution is generally provided by the supplier.

6) generally requires the distribution station as a "reservoir", storage vendors and loading quantities of goods, according to the store needs.

7) the model is generally based on the market by the business enterprise demand by the spontaneous formation.

int distribution model of small and medium sized enterprises (trade) enterprises

Due to reasons such as complementary goods homogeneity or distribution area, some production (business) enterprises to reduce logistics cost and improve the efficiency of distribution, distribution mode of integration of the related logistics resources to meet the distribution requirements and the use of multiple customers.

1) some small and medium-sized production enterprises (business) because of the business relationship, or complementary reasons such as distribution area, sharing capacity by alliance, improve vehicle loading rate, to reduce the cost of distribution, joint distribution to improve the efficiency of distribution and use.

2) distribution service scope is limited to carry out the cooperation of each enterprise's distribution customers, more closed, social openness is weak.

3) the establishment or outsourcing of logistics enterprises is the main body of supply and distribution operations.

4) distribution line according to the requirements of the goods stores, relatively fixed.

5) from the production (business) enterprise to customer distribution of the whole process of self or outsourcing of logistics enterprises.

6) the model is generally based on the principle of mutual benefit by the relevant enterprises to form a spontaneous, but need enough information so that the relevant enterprises can find the possibility of cooperation in order to promote the development of the model.

Large electronic business platform

Online business platform operators will be focused on one or several suppliers of products, according to the distribution needs of online shopping customers, to co-ordinate the development of distribution programs, unified for the online shopping customer distribution.

1) business platform operators to improve service level and competitiveness of electronic business platform, through the implementation of joint distribution, efforts to improve the distribution efficiency, shorten the delivery time, and the distribution of cost control in an acceptable degree.

2) business platform operators through the scale and influence of the platform to gather the supply of goods, through the downstream customer order data analysis, optimize the distribution organization.

3 ) the general need for a hierarchical system of stations to meet the demand for the distribution of over dispersed orders.

4) has a strong social openness, the use of this business platform businesses are commissioned by the business operators can be entrusted to provide distribution services. 


\section{LOGISTICS ENTERPRISE PROFESSIONAL DISTRIBUTION}

\section{Single large logistics enterprise}

With cold chain, medicine, dangerous goods and other large professional logistics enterprises as the core, the integration of the relevant professional field of customer distribution needs, to develop a distribution plan, the general logistics enterprises to implement special vehicles to implement common distribution.

1) to attract more customers, expand the scale of transport and achieve scale benefit by improving the professional logistics capability and improving the logistics service level.

2) distribution service scope is limited to the professional logistics enterprise contract goods distribution, with a strong social openness, the goods of the contract depends on the professional logistics enterprise transport capacity.

3) professional logistics enterprises are the main body of the contract supply and organization and transportation.

4) the general need for storage and distribution station of different goods cargo stowage.

5) general logistics enterprises not only undertake upstream from the manufacturer to distribution station transport, from the station to the downstream distribution also assume the distribution of stores.

6) transport lines are fixed according to different customer needs, with no fixed.

7) professional logistics enterprises, the need to establish a classification distribution system

Logistics alliance mode

By several distribution enterprises to form a corporate alliance, integrated share supply, station, vehicle, information systems and other resources, to co-ordinate the development of distribution programs, arrangements for the alliance of internal vehicles for the alliance business customers to provide distribution services.

1) grasp the different resources of logistics enterprises, in the integration of resources are complementary, there is willingness to cooperate or alliance, to the advantage of complementary, reduce costs, and seek common development.

2) logistics enterprises alliance is the main body of the station, vehicles and other resources, and to make transport routes and plans.

3) the supply of goods by the alliance members were hired, or by the alliance enterprises to launch a joint brand contract.

4) stations and vehicles are shared by all members of the alliance, and the benefit distribution mechanism that can be accepted by all parties can be used by the members of the alliance.

5) society has strong openness, where the identity of the logistics service capabilities of enterprise alliance can be entrusted to the owner of joint distribution alliance enterprises.

6 ) is generally a long-term contract logistics, transport lines are more fixed.

\section{CENTRALIZED DISTRIBUTION MODE IN THE DISTRIBUTION STATION AS THE CORE}

Large distribution center distribution

From the distribution center station operators contract cargo warehousing, the owner of cargo in the station, the owner of the integrated distribution demand, develop the delivery plan, freight vehicles assigned to the assigned station unified distribution, improve the efficiency of transport vehicles

1) distribution center station operators to improve operational efficiency, integration of warehousing, transportation and other resources, through the car loading optimization of transport organization, 
reduce transportation costs, improve service quality, in order to attract more owners entrust their warehousing and transportation, also attract more logistics enterprises station.

2) distribution center operators have a clear market positioning, for the whole society to undertake distribution services for industrial and commercial enterprises, has a strong social openness.

3) distribution center operator is the main body of the contract supply, and optimizes the transportation organization.

4) station is the core resources to attract customers, organize transportation capacity, and make the transportation plan.

5) distribution center without owned vehicles, distribution logistics enterprises or social organizations in the field of vehicle station station to take the upstream manufacturers and downstream transport station field to customers.

6) is generally a long-term contract logistics, transport lines are more fixed.

7) the construction of large distribution centers for the government planning, the construction of the mode of operation of enterprises.

City end joint distribution

In the community or school, with a km radius, the establishment of joint distribution terminal site, undertake terminal logistics distribution business e-commerce, express logistics and professional logistics and distribution enterprises, unified distribution of goods, improve the efficiency of distribution

1) is the integration of the $\mathrm{B} 2 \mathrm{C}$ end of the distribution services.

2) need to have the logistics company specialized management end common distribution site.

3) from the logistics enterprise to the end of the distribution of the site shall be borne by the transport logistics enterprises, the end of the distribution to customers to pick up.

4) has a strong social openness, as long as the target customers in the community or school area, can use the model.

5) and the common distribution mode in a specific region is different, the former is to meet the needs of the distribution of $\mathrm{B} 2 \mathrm{C}$, the latter is to meet the needs of $\mathrm{B} 2 \mathrm{~B}$ distribution.

\section{WITH INFORMATION TECHNOLOGY AS THE CORE OF THE JOINT DISTRIBUTION}

Based on the technology of mobile Internet application software development, integration of social resources and capacity, according to the real-time demand information distribution, intelligent routing planning, for businesses and individuals to provide billing delivery service, and support mobile payment, customer convenience, improve efficiency.

1) through the use of mobile Internet technology, organize social capacity, to provide convenient, price, quality and distribution services, attract many shippers using service platform (APP) based on the support of mobile Internet technology, through real-time orders, screening convoys, the vehicle loading rate is highest, the shortest distance principle of Intelligent Transportation route planning.

2) distribution services include all customers who are willing to use the distribution platform, with strong social openness.

3) light asset platform company, application software is the core competitiveness, integration, but does not have the station, vehicles and drivers, etc..

4) with the standardization of the operating system and mobile payment technology, the volume of goods (weight) billing city logistics.

5) by scientific and technological progress and the formation of the market.

\section{UNIFORM DISTRIBUTION WITH SPECIFIC RESOURCES}

\section{Centralized distribution of supply}

The geographical position is relatively concentrated industrial park or wholesale market in many businesses as the service object, by the joint venture or outsourced to one or several logistics enter- 
prises together, distribution needs more customers in the integration of supply, develop the distribution plan, by the logistics vehicle or the integration of social distribution vehicle.

1) the park management committee, the management of wholesale markets or the local government to reduce traffic congestion, improve investment in the region or city environment, guide enterprises and businesses or organizations focus on transport demand, transport route optimization, implementation of joint distribution.

2) distribution services are limited to a certain source of goods to the relevant production (business) sales customers, relatively closed, with a certain social openness.

3) logistics enterprises are the main body of supply organization and line planning design and organization operation.

4) transportation plan changes according to different cargo transport demand, transport routes, vehicles, time is not fixed.

5) generally need to station facilities will be the supply of different goods to concentrate on the fight.

6) the model generally requires the supply of centralized managers or the government to guide the formation of.

\section{Customers focus on distribution}

With a pattern on the contrary, for a specific area of the city center to ease the traffic pressure, such as a commercial center, tourism commercial street, CBD core area, a station inside the area of the city joint distribution needs to focus on the outside of the region, by $\mathrm{CO}$ ordinating the development of station distribution plan, unified by the logistics enterprises or vehicles the integration of social vehicles to the area distribution

1) strong to solve the distribution demand of local area and city traffic congestion, prominent contradictions, through the joint distribution mode, reduce traffic, alleviate traffic congestion, improve air quality.

2) focus on serving the needs of customers in a specific region, with a certain social openness.

3) generally require distribution station to undertake the supplier of goods, and make reasonable carpool stowage.

4 upstream from the manufacturer to the distribution center of the transportation by the supplier to carry the general, logistics enterprises to co-ordinate the distribution center to a specific area of distribution.

5) generally requires the government to guide, logistics enterprises to operate in order to integrate the region's downstream distribution needs.

\section{Based on the joint distribution mode of special channel}

To ease the traffic pressure in the city, the river, rail and other large capacity of channel resources, the ends of the channel region city joint distribution demand concentrated in the vicinity of the channel inside the station, by the station full use of channel capacity, develop the distribution scheme for distribution.

1) the purpose of this model is to ease urban traffic congestion, improve air quality, by the government departments to guide or organize the logistics enterprise to give the right to operate the channel capacity and the common distribution model.

2) to make full use of the characteristics of the channel, rail transport capacity of low emissions, reduce transport costs, reduce emissions, but limited to the rail, the restrictions on the mode of transport, distribution efficiency may be reduced.

3) need to be based on the channel transport and distribution requirements, in particular the supporting loading and unloading site, handling equipment, etc..

4) this mode is mainly to reduce the negative effect of the society, therefore, it needs the government to lead, and even lead to the formation of the

\section{Urban goods taxi}

To ease the traffic pressure in the city, government departments by defining a specific time and specific regional freight vehicle right as a means to reduce forced truck into the truck, chartered wayleave accept orders, develop the distribution scheme for distribution. 
1) to control the number of vehicles entering the city by means of a franchise permit, in order to reduce the traffic volume and ease the traffic pressure.

2) distribution scope is the specific area of the whole city, with strong social openness.

3) a licensed enterprise must have a distribution vehicle that meets the requirements.

4) is the government through the administrative means to intervene in the market, a kind of distribution.

\section{reference}

1)Deng Ai-min, Wang Shao-mei, Zheng Hong-yu. The Analysis of City Distribution Forming Mechanism [J] Wuhan University of Technology ( Social Science Edition) December 2005

2)Xu Tong-lian, Sun Bao-feng, Fu Zhong-ning, Xu Hong-mei. Study on the Model of Fractal Management of Joint Distribution [J] Journal of Highway and Transportation Research and Development Vol. 23 No. 3 Mar. 2006

3)Luo Jian-feng. Matches Together Delivers the Pattern Analysis and the Implement Action research [J] Supply Chain Sep. 2007

4)Han Li-juan. Research on the Mode of Urban Joint Distribution [D] Wuhan University of Technology Dec. 2013

5)Tang Xiao-chun, Wu Yin-long, Zhao Liang. The Joint Distribution of World's Development and the Development Prospects of China. [J] Journal of Highway and Transportation Research and Development Jul 2013

6)Xu Tong, Luan Kun, Xu Hong-mei. Study of the Strategy on Fractal Management of Joint Distribution [J] Journal of Highway and Transportation Research and Development 2006. 06

7)Wang Peng-yuan. Research on the Terminal Distribution of B2C Electronic Commerce [J] ChangAn university. Jun. 2015

8)Zong Gao-qin. Research on Terminal Joint Distribution for Small and Medium E-Commerce Enterprises [D] Beijing Jiaotong University Mar. 2015

9)Liu Ai-jun. A Research on Agriculture Logistics-A Perspective from Enterprises [D] Nanjing Agricultural University Jun. 2007 